\title{
Correction to: Enhanced adsorption of phosphorus in soil by lanthanum-modified biochar: improving phosphorus retention and storage capacity
}

Di Zhao ${ }^{1,2} \cdot$ Yuan Luo ${ }^{1,2} \cdot$ Yi-yang Feng ${ }^{1,2,3} \cdot$ Qiu-ping He ${ }^{1,2} \cdot$ Li-sheng Zhang $^{1} \cdot$ Ke-qiang Zhang ${ }^{1,2} \cdot$ Feng Wang $^{1,2}$ (D)

Published online: 12 August 2021

(C) Springer-Verlag GmbH Germany, part of Springer Nature 2021

Correction to: Environmental Science and Pollution Research https://doi.org/10.1007/s11356-021-15364-6

The correct presentation of Figure 9 has been redrawn and submitted because of the partial text deviation caused by the problem in Figure 9 itself.

Publisher's note Springer Nature remains neutral with regard to jurisdictional claims in published maps and institutional affiliations.

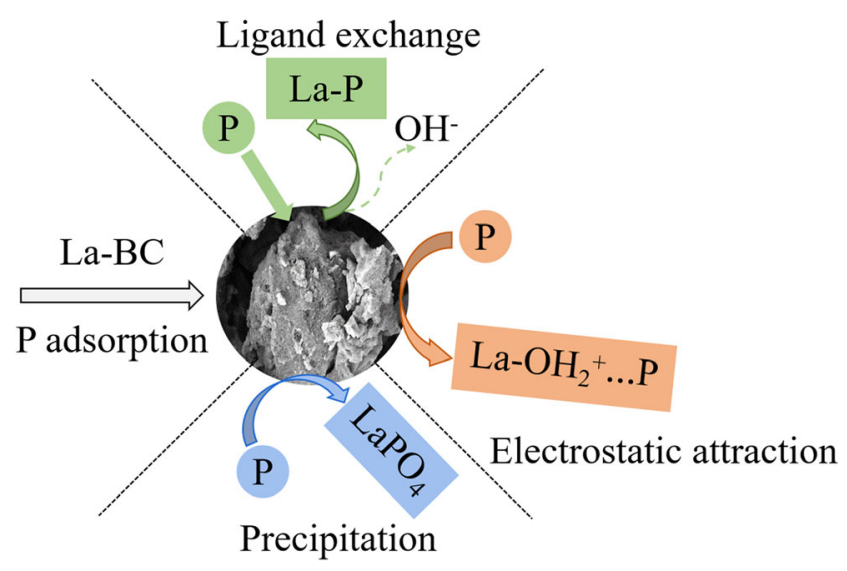

Fig. 9 A schematic diagram for the mechanism of phosphate adsorption on La-BC

The online version of the original article can be found at https://doi.org/ $10.1007 / \mathrm{s} 11356-021-15364-6$

Feng Wang

wangfeng_530@163.com

1 Ministry of Agriculture and Rural Affairs, Agro-Environmental Protection Institute, Tianjin 300191, China

2 Dali Experimental Station (Dali Original Breeding Farm) of Agro-Environmental Protection Institute, Ministry of Agriculture and Rural Affairs, Dali 671004, China

3 College of Resources and Environment, Yunnan Agricultural University, Kunming 650201, Yunnan, China 